\title{
Project Performance Model for Construction Companies in Iraq
}

\author{
Ammar Ali ${ }^{1}$, K. Ramanathan ${ }^{2}$ \\ Post Graduate Center, Limkokwing University of Creative Technology, Malaysia ${ }^{1}$ \\ Post Graduate Center, Limkokwing University of Creative Technology, Malaysia ${ }^{2}$
}

\begin{abstract}
The performance of construction companies is crucial for the economic development of every country and there are various factors which affect their performance of Construction Company. Past studies on project performance have been skewed towards project factors such as client, contractor, consultant and material. Through the literature review, it was noticed that a research gap exists, whereby, for the success of a project, not only are project factors important, but organizational factors are important too. Taking a lead from here, the most important organizational factors, such as leadership, organizational culture, innovation and learning organization were chosen and used in this study to examine and investigate the impact of these organizational factors on project performance. Therefore, the objective of this study was to examine and investigate the impact of project and organizational factors on the project performance of construction companies in Iraq. A pilot study was carried out and the instrument reliability was ascertained. The population for this study was the construction companies in Iraq registered with the industry of construction and housing under the level 7 category. This quantitative study was carried out with a survey questionnaire. 500 questionnaires were sent to managers (Construction Manager, Project manager, Project executive, Site Supervisor) of construction companies and 411 responses were received with a response rate of $33.61 \%$. The collected data were analyzed using the Statistical Package for Social Science version 25 (SPSS) for descriptive, reliability, validity and relative importance index analysis and Measurement and Structural Model using Partial Least Square Structural Equation Modeling (PLS-SEM) technique. The results of the study indicate that organizational factors have a greater significant impact on project performance over project factors. Thus, the outcome of the study is useful for the construction industry practitioners to understand the importance of organizational factors and to implement them in their organizations to improve project performance.
\end{abstract}

Keywords: Partial Least Square Structural Equation Modeling (PLS-SEM), Statistical Package for Social Science version 25 (SPSS)

\section{INTRODUCTION}

The construction industry is the backbone of economic transformation in any country. Universally, the performance of the construction industry is a direct indicator of the state of a country's economy, and its performance is vital and crucial for the country's economic activities. The higher the performance of the construction industry, the higher the economic growth and vice versa. As most of the economic activities of nations are spun around the construction industry, it is of paramount importance for every country to ensure that the construction industry is doing well and the organizations involved in these activities are also doing well. There are many factors which impact the performance of the construction projects in each country. Some factors are unique to the project itself, some factors are unique to the country itself, and some factors are common for all the construction projects globally. According to [1], there are two distinctive groups of factors, which impact project performance in construction companies. The first group of factors is known as hard factors (project-related factors) and the second group of factors is known as soft factors (organizationalrelated factors). Project-related factors refer to factors which directly impact construction project performance, such as client, contractor, consultant, material, labour and equipment, external and project management tools/techniques related factors. On the other hand, organizational-related factors refer to indirect factors, which impact project performance indirectly, such as leadership, organizational culture, innovation and learning organization. Studying these factors impacting project performance of the construction companies is important for the sustainability and growth of the construction industry.

\section{LITERATURE REVIEW}

\section{a. Project Factors}

Long [3], found in his studies, that project management personnel, their technical tasks, monitoring and feedback, communication and troubleshooting, are some of the factors positively correlated for project success in manufacturing 


\title{
International Advanced Research Journal in Science, Engineering and Technology
}

\author{
Vol. 6, Issue 6, June 2019
}

projects in Iraq. [2], found in their studies, that success judgment by various stakeholders during conceptualization, planning, implementation and closing phases of the project life is critical for the success of the projects in developing countries in not-for-profit international development projects. They also found that project planners and designers are important for project success. [6], found in their studies, that lack of communication between parties in a project is a significant factor affecting project performance in Iraq.

\section{- Contractor factors}

Long and Lien [3] stated that stakeholders, such as subcontractors and their interest in a project, is a key factor for project success along with other CSFs. [9], found in their studies, that problems with subcontractors and mistakes during the construction stage, are the most important causes for delays in construction projects in Iraq. [8] found in their studies that, financial difficulties, inadequate experience, poor site management, improper planning and construction mistakes / defects are some of the contractor related causes, which leads to delay in construction projects in Iraq. [11], found in their studies that, the critical sources of delay in Iraq government related construction projects are insufficient contractor's working capital and poor site management practices of the contractor. [6] stated that delay by subcontractors is one of the causes for delay in construction projects in Egypt.

\section{Consultant factors}

Long and Lien [3] found in their studies that, role of consultants in a project is important and their interest in a project will lead to less technical problems and will lead to project success. [12], found in their studies, that consultant factors are one of the four main causes for delays in construction projects in Iraq. [14] found that consultants are important for project success in not for-profit international projects in developing countries. [13] found in their studies that, consultant's lack of experience is one of the cause for delay in construction projects in Iraq. [20], found in their studies that, the critical source of delay in Iraq government related construction projects is delay in approvals by consultants. [11] stated that consultant design mistake is one of the causes for delay in construction projects in Egypt.

\section{- $\quad$ Material factors}

Cannon [32] explained in his research that there exist different structures and supplier relationships between various countries, such as the USA, the European Union (EU) countries and Japan. These different supplier structures and relationships significantly lead to difference in project performance in these countries. [22] found that, supplier's performance in terms of supplying material on time with right quality is an important factor for the success of the projects. [13], found in their studies, that shortage of materials, during the construction stage is one of the top 10 causes leading to time and cost overruns in construction projects in Iraq. [14] found in their studies that, delay in delivery of materials to site and increase in material prices are the material related causes for the delay in construction projects in Iraq. [15], found in their studies that, the critical source of delay in Iraq government related construction project is scarcity of raw materials. [16], found in their studies, that fluctuation in raw material prices from suppliers is a significant factor affecting project performance in Iraq. [17] stated that shortage of materials from suppliers is one of the causes for delay in construction projects in Egypt.

\section{- $\quad$ Leadership factors}

Demirkesen and Ozorhon [25] argued that apart from many CSFs which influence project success or failure, a project manager's management and leadership skills are important for the project's success. [18] suggested that top management of project management companies must clearly specify project objectives as early as possible even before the project starts. According to [19], leadership is distinctively different from management, where management is about dealing with complex situations while leadership is about dealing with changes in the organization. He also stated that most of the organizations are over-managed and under-led. Kotter further stated that successful and well-led businesses tend to recognize and reward people who successfully develop leaders. [21], found in their studies, that leaders in an organization should not only focus on time, cost and quality performance, but should also focus on the strategic fit of the project to the organization's objectives and the project's side effects to the organization. [23], who developed a project excellence model linking CSFs and project success, found that leadership and teamwork are the most critical factors for project success. [24], found in their studies, that top management support and leadership are important for project success. [25], found in their research, that structural changes and changes in organizational performance are only possible with top management's support and leadership. [27], found in their research study, that previous studies on project success have ignored the leadership roles of project managers and leadership styles and competency of project managers does not have a significant impact on project success due to the unique and temporary nature of the projects. [26], found in his research, that dynamic leadership is the key factor for high performance in organizations.

\section{- Organizational culture factors}

Demirkesen and Ozorhon [25] argued that project management team members' technical background is crucial for the success of projects. However, [23], found in their research, that a project management team is not fully responsible for 


\title{
International Advanced Research Journal in Science, Engineering and Technology
}

\author{
Vol. 6, Issue 6, June 2019
}

the success or failure of their project. They further suggested that the project management team members' role should be appreciated. [30] stated that keeping track of the risks and an adequate up-to-date risk management plan coupled with clear ownership of risks for individuals in an organization is an important factor for achieving project success. He further added that maturity of the organization's processes, project matrix structure and effective benefits delivery as well as line management staff in an organization will pave the way for a project's success. [33] stated that organizational policies and strategies significantly relate to project performance. [31], found in their studies, that a significant relationship exists between corporate culture and organizational commitment. [30], found in their studies, that top organizational structure and trouble-shooting culture of an organization are significantly related to a project's success. [34], found in his research, that limited knowledge on how project organizations behave in the construction industry, has an impact on project success. He also found that corporate issues and their impact on project success have not been studied in the construction industry.

\section{Innovation factors}

Dubois and Gadde [], found in their studies, that the construction industry's pattern of connections, short-term productivity and fast decision-making hampers innovation. They also found that the construction industry players behave differently with one another and since projects are temporary in nature, not much attention is paid to innovation and thus, not promoted. Additionally, they stated that government regulations and industry standards hamper innovation in the construction industry. [37], found in his research that, innovation as a concept and its impact on project success have not been studied in detail in the construction industry. [39], found in their research studies, that innovation capital has a non-linear (inverted $U$ shape) relationship with firm performance, whilst innovation and information technology (IT) capital have a positive effect on firm performance. They also stressed that more investment in intellectual capital is not good for an organization. [20], found in his research, that an action-learning approach can help to create a dynamic culture of innovation, which will lead to organizational performance. [33], found in his research, that procurement methods used for building construction projects, are a determining factor for innovation in the construction industry. He further stated that, innovation can be the strategic option for complex projects in the construction industry.

\section{Learning organization factors}

Garvin [31] stated that many of the continuous improvement programs in organizations fail and suggested three critical issues, i.e., well-grounded definition, clear operational guidelines and better tools for measurement for learning organizations to be successful. Garvin also suggested that systematic problem solving, experimenting new approaches, learning from past experiences, learning from best practices of others and transferring knowledge quickly and efficiently across the organization can help the organization to be successful. [30] stated that performance technologists (training managers) in an organization should treat their employees as clients and should enable the employees to master the five principles of learning organization, i.e., systems thinking, shared vision, learning, personal mastery and mental models. Gordon further insisted that employees in a learning organization should have common purpose, common language, common processes, the resources needed and the authority to make decisions to enhance organizational performance. [41], found in their studies, that technological changes and speed of change is an enabler for learning. They believed that in the future, learning will become inevitable, learning will become part of the organizational culture, learning will change the business processes and learning will become an important aspect to promote individual as well as organizational performance.

\section{RESEARCH METHODOLOGY}

The tool used to achieve the relationship between the project and organisational factor and project performance in this study is by developing a conceptual framework. Factor is a variable that can have a significant impact that delivers measurable improvements to the project success. Organisations/companies look to forecasting tool to help them speed their progress toward performance improvement, and to guide them around pitfalls that might otherwise slow or even halt their initiatives of project performance. Therefore, in order to improve the project performance, it is essential to determine the factors in the current project management practices. In order to achieve this, the variables for project success are essentially important to be identified and established towards achieving the objective of this study. The target population of the questionnaire survey will be the project manager, architect, engineer, builder and who have experienced in the construction industry in Iraq. This research is limited to Babylon Iraq only since this country running many construction projects. Sets of the questionnaire will be distributed to identify the critical success factors project management practice in Iraq. The analysis of data from the questionnaire's responses can provide precise data from which tables can be produced. Pilot survey will be also being conducted to view the current scenario of construction industry and feedback on the process and procedure in the respective organization. A pilot study will be carried out to test the relevance and comprehensiveness of the questionnaire before it will send to the respondents in the industry. 


\title{
International Advanced Research Journal in Science, Engineering and Technology
}

\author{
Vol. 6, Issue 6, June 2019
}

\section{RESULTS}

\section{a. Measurement Model Using Smart-PLS}

The dimension Model or since it's described in PLS-SEM the outside model, introduces that the relationship among constructs as well as also the index variables [21]. The attention on model analysis depends upon the dimension model. Assessment of all PLS-SEM quotes, lets the researcher to inspect the validity and reliability of this construct step. Specially, multi-variate measurement empowers researcher to utilize several factors for measuring a concept which result in significantly more precise steps. This anticipated enriched adequacy presumes that utilizing several factors to check one concept will insure just about all aspect of this particular concept. In any case, that may result in a far more legitimate measurement of this concept. Multivariate investigation with its nature empowers the manipulation of multivariate dimension in research which results in an even far more accurate acquiring of this research. The aim of multivariate dimension is always to lessen the dimension error and permit the researcher to particularly locate the anomalies and react to these precisely as it regards research findings [21].

\section{- Construct Reliability}

Reliability could be the capacity of questionnaire to create exactly precisely the exact very same results below identical states. Customarily, construct reliability is figured by inner consistency reliability with Cronbach's Alpha coefficient (CA) and Composite reliability (CR). Constructs using top CA values imply those items inside of the construct possess precisely exactly the exact identical selection and significance [21]. Fundamentally, both CA and CR the two quantify precisely exactly the exact identical item (inner consistency). But, CA supposes that most indications are weighted in place of CR which believes indicators have various loadings [21]. The suitable significance of Cronbach's Alpha and mix vulnerability is equivalent to above 0.7 , whereas values under 0.6 signify not enough reliability [21]. From the current research, combination reliability and Cronbach's alpha have been analyzed with PLS algorithm in wise PLS. Table 1 demonstrates most composite reliability and Cronbach's Alpha value match up with the proposed values. But, CA for several constructs," Task inter-dependence (0.694), Social Impact (0.612), also Intention to embrace (0.663), ended up beneath 0.7 that has been okay as signaled by [21].

\section{Convergent Validity}

The aim of convergent validity is always to inspect the scope that a calculate favorably contrasts with other steps of very related construct. Implementing the domain model is going to result in handling the index of the reflective construct by way of another approach so as to gauge precisely exactly the exact very same construct. Being a result with the, those things that would be the step of the specific construct should exude or talk about quite a great quantity variance. For analyzing convergent validity, you can find just two famous procedures that are employed by researchers, the more outer loadings of these signs, the typical variance extracted (AVE) [21]. Average variance extracted (AVE) is corresponding to this communality of the construct-up. For that reason, to concur that an construct defines over $1 / 2$ of those variance of this index that the AVE worthiness of 0.50 or more ought to be reached from the construct, an AVE less-than 0.50 introduces greater mistake in those things compared to variance clarified through the construct [21]. Therefore, right following assessing the outside loading of this construct their AVE has been assessed along with the construct attained the brink (see Table 1).

Table 1: Average Variance Extracted (AVE) Test Result

\begin{tabular}{|l|l|l|l|l|}
\hline & CA & rho_A & CR & AVE \\
\hline CONS & 0.739 & 0.744 & 0.835 & 0.559 \\
\hline CONT & 0.834 & 0.835 & 0.883 & 0.601 \\
\hline IN & 0.772 & 0.772 & 0.854 & 0.594 \\
\hline LE & 0.846 & 0.851 & 0.887 & 0.567 \\
\hline LEA & 0.781 & 0.798 & 0.850 & 0.533 \\
\hline MA & 0.806 & 0.812 & 0.865 & 0.562 \\
\hline Moderating effect 1 & 1.000 & 1.000 & 1.000 & 1.000 \\
\hline Moderating effect 2 & 1.000 & 1.000 & 1.000 & 1.000 \\
\hline ORG & 0.809 & 0.898 & 0.843 & 0.523 \\
\hline PF & 0.859 & 0.862 & 0.899 & 0.640 \\
\hline PP & 0.807 & 0.807 & 0.912 & 0.838 \\
\hline PT & 0.818 & 0.818 & 0.873 & 0.579 \\
\hline
\end{tabular}




\title{
International Advanced Research Journal in Science, Engineering and Technology
}

\author{
Vol. 6, Issue 6, June 2019
}

\begin{abstract}
Discriminant Validity
Discriminant validity can be a dimension which confirms if every single construct is exceptional. Discriminant validity exemplifies as to the degree that the constructs within a model are not the same as each other. Hence, all constructs ought to be correlated to their particular measures compared to different constructs. Two actions of discriminant validity are usually indicated, Fornell-Larcker's standard (for construct degree discriminant validity) and cross loading (for thing amount discriminant validity) [21]. Fornell-Larcker implied the square foot of a construct's AVE ought to be higher compared to the correlations of their different constructs from the model [21] proposed analyzing cross-loading included factor loading to be certain each measuring thing inside of just construct was bigger compared to most its cross-loadings in column and row. This usually means that should each index's loading is high because of the designated construct in comparison to almost any constructs, then it might be inferred the distinctive constructs' indexes aren't interchangeable. For quantifying discriminant validity, the researcher ought to employ two techniques [21]. Very first is analyzing discriminant validity by checking the cross loadings of every and every index. To test cross loading, a specific index outer loading to the applicable construct needs to be more than each its loadings on additional constructs. Discovering the cross loadings that are higher than index's external loading signifies issues seeing discriminant validity exist. For that reason, to test discriminant validity with the goal with the study, cross loading of indexes has been analyzed and each one them accomplished the essential requirements.

The next test for discriminant validity is called Fornell-Larcker that's really a more rigorous method for measuring discriminant validity. This approach compares between square root of AVE value and latent variable correlations. To pass this measurement, AVE of a construct should be more compared to its greatest significance with any additional construct. This means AVE should be more compared to squared correlation together with any other construct [21]. As such, to ensure discriminant validity of the constructs of this research dimension model, Fornell-Larcker test has been performed, and all of the constructs achieved the significance of passing the evaluation. As the adequacy of this dimension model has been supported (see figure 4.5) during the very first phase of the investigation [] it had been acceptable to move into this following stage that's analyzing the structural model, also will present be discussed at the following section.
\end{abstract}

\section{a. Structural Model Assessment using smart PLS}

As the construct steps validity and reliability has been supported, at the upcoming thing the test of this structural model result has been discussed. This consists of assessment of this model's predictive capacities the relationship amongst the constructs.

\begin{abstract}
Described Variance (R2)
$\mathrm{R}^{2}$ value (coefficient of determination) is a popular measure to evaluate the structural model. $\mathrm{R}^{2}$ might be understood to be the step of this predictive precision for its model plus it could be computed since the squared correlation amongst a distinct endogenous factor's true and predicted worth. $\mathrm{R}^{2}$ reflects the collective impact of Allergic constructs on endogenous latent factor. Since $\mathrm{R}^{2}$ is the squared correlation of predicted and actual worth, the sum of explained variance from the variables by each the exogenous factors connected to this, can be represented by $R^{2}$ [21]. The reach of significance for $\mathrm{R}^{2}$ is to 1 , inside of this array of value increased values signify high rate of predictive precision. $\mathrm{R}^{2}$ values such as endogenous latent constructs might be clarified as huge (0.67), moderate (0.33), also modest (0.19) [21]. For that reason, $\mathrm{R}^{2}$ has been evaluated for endogenous latent variables with the research the results have been given. $\mathrm{R}^{2}$ signifies the sum of variance independent factor (s) which is "clarified" or" accounted" from the individual factors. The value of $\mathrm{R}^{2}$ fluctuates and based on [21], model with $\mathrm{R}^{2}$ like $0.67,0.33$, along with also 0.19 are regarded as large, medium, and weak respectively. Hence, the greater significance of $\mathrm{R}^{2}$ escalates the numerical capacity of this structural model. As an instance, $\mathrm{R}^{2}$ \# inch ensures which individual factor is/are outlining every one of the variants of this dependent factor. Inside this research, sensible PLS algorithm work has been conducted to compute the $\mathrm{R}^{2}$ for most determined factors. Results demonstrate the overall called $\mathrm{R}^{2}$ for intent to embrace is 0.421 meaning that 42 percent of their variance in human intent to embrace post-secondary collaborative instruction software will be clarified with its individual factors. Personalization, freedom, cooperation, undertaking non-routineness, and undertaking interdependence can spell out 48.6percent of their variance of activity technology fit (TTF). Meanwhile, the intimacy along with all many others, self-efficacy, technology encounter, energy expectancy, and activity technology suit make clear 63.7percent of variance in Performance Expectancy. Last but not least, 35.3percent of variance in attempt expectancy is clarified by intimacy with the others, self-efficacy, and technology encounter. Table 2 introduces the Rsquare of determined factors while inside the research model that all fall over the "medium" self-explanatory strength.
\end{abstract}

Table 2: R-Square of Dependent Variables

\begin{tabular}{|l|l|}
\hline & R-Square \\
\hline Company Performance & 0.959 \\
\hline
\end{tabular}




\section{International Advanced Research Journal in Science, Engineering and Technology}

Vol. 6, Issue 6, June 2019

\section{Path Coefficient $(\beta)$}

Course co-efficient intends to analyse the importance of the route relationships within a structural model [21]. To put it differently, route coefficient may be the quantity of modification independent factor that results from way of a 1 component change in separate factor, whereas other individual constructs are retained steady. Together with the Smart PLS algorithm outcome signal, the relationships between dependent and independent factors $(\beta)$ have been analysed. Nevertheless, in clever PLS so as to try exactly the substantial degree of connections, t-statistics for several avenues are produced employing the wise PLS boot-strapping functionality. T-value is a standard which helps you determine the exact importance amount of $\beta$ between determined and individual constructs. $\mathrm{T}=3.091 \mathrm{P}<0.001, \mathrm{t}=2.326 \mathrm{P}<0.01$, also $=1.645 \mathrm{P}<0.05$ are okay significance for $\mathrm{T}$ value in numerous meanings grades. To just simply accept the suggested hypothesis from the structural model, the trail coefficient involving independent and dependent factors should really be more significant. [21] considered that course coefficient the same or over 0.1 accounts fully for some impact over this model. Results of course assessment ( $\beta$, t-value, and P-value) permit the researcher to reject or confirm every hypothesis and comprehend that the potency of their relationship between independent and dependent factors.

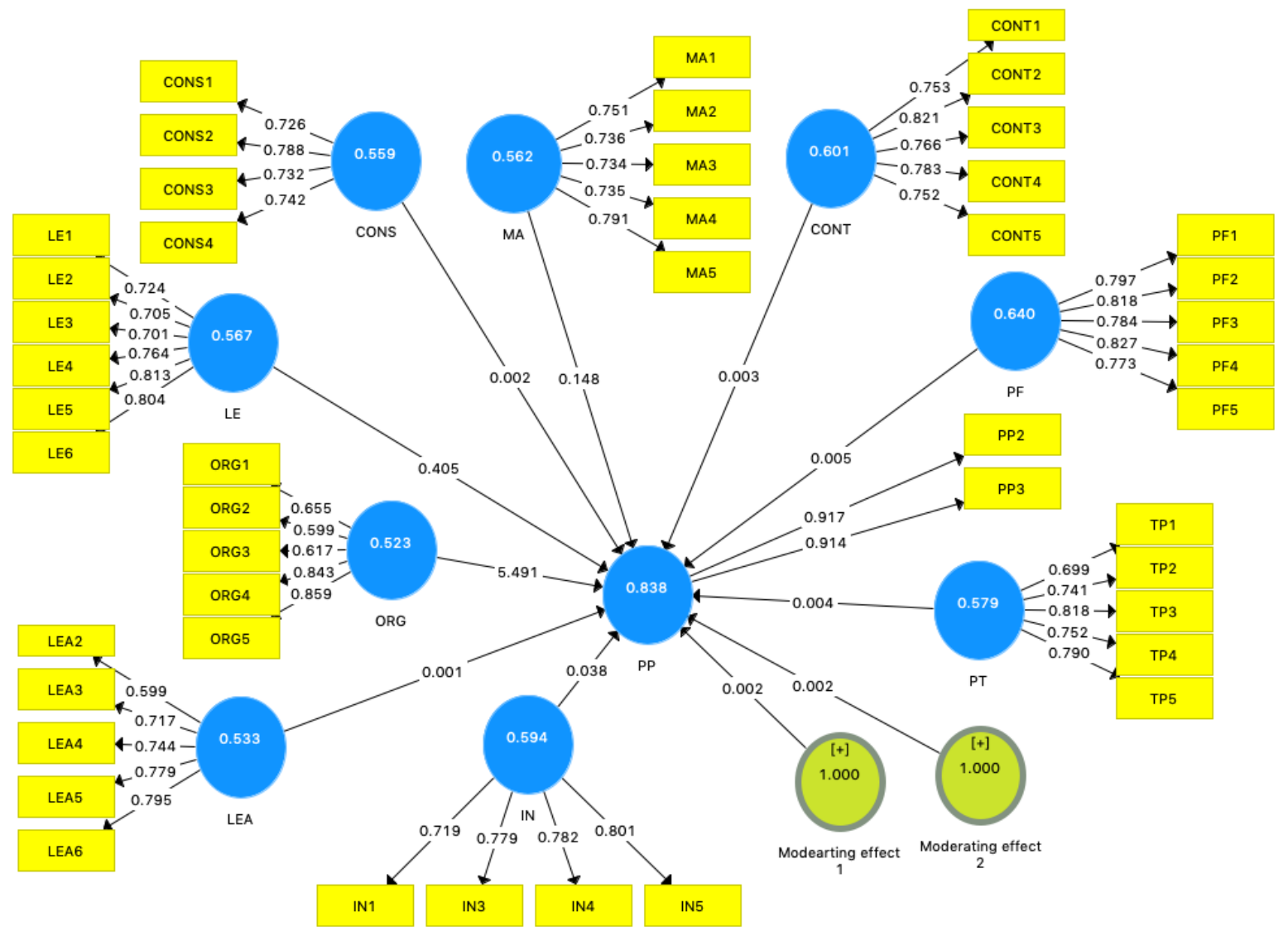

Figure 1: Results of PLS Algorithm Analysis

Table 3: Path Coefficients $(\beta)$, T-Statistics and its Significance Level

\begin{tabular}{|c|c|c|c|c|}
\hline Dependent Variable & & Path Coefficient & Significant level & P Values \\
\hline \multirow{11}{*}{$\begin{array}{l}\text { Performance } \\
R^{2}=0.959\end{array}$} & CONS -> PP & 0.360 & & 0.000 \\
\hline & CONT -> PP & 0.055 & & 0.001 \\
\hline & IN -> PP & 0.079 & & 0.001 \\
\hline & LE -> PP & 0.179 & & 0.000 \\
\hline & LEA -> PP & 0.589 & & 0.004 \\
\hline & MA -> PP & 0.162 & & 0.000 \\
\hline & Moderating Effect 1 -> PP & 0.087 & & 0.003 \\
\hline & Moderating Effect 2 -> PP & 0.173 & & 0.001 \\
\hline & ORG -> PP & 0.016 & & 0.000 \\
\hline & $\mathbf{P F}->\mathbf{P P}$ & 0.360 & & 0.000 \\
\hline & PT -> PP & 0.055 & & 0.002 \\
\hline
\end{tabular}




\section{International Advanced Research Journal in Science, Engineering and Technology}

Vol. 6, Issue 6, June 2019

Accordingly, within this research, PLS algorithm has been conducted to figure course coefficients (see Figure 6.1). Boot-strapping procedure has been completed with 209 instances and 1000 samples to get the need for just about every structural pathway (i.e. that the T value).

This research study is that the previous studies on construction companies' project success/performance predominantly studied project performance in terms of time and cost only. Very few studies have discussed the iron triangle (time, cost and quality) to measure project performance. In this research, five dimensions (time, cost, quality, safety and financial dimensions) of project performance were researched and the results are explained. Surprisingly, three dimensions of project performance (safety, financial and quality dimensions) emerge as the most important project performance factors, which is a contribution to the existing body of knowledge.

This study is on the identification of project and organizational factors which have a significant impact on sector-wise construction companies' project performance. This is another contribution to the existing body of knowledge.

The fifth theoretical contribution is on the use of various theories, such as the transaction cost economics, leadership, organizational culture, innovation and learning organization theories, to strengthen the existing loosely coupled project management theory. These theories are used to develop the research framework used in this study. As the performance of construction projects is dependent on the associated transaction costs, leadership skills of the project managers, organizational culture of the construction companies, innovation and learning initiatives adopted, application of these theories for construction companies' project performance is another contribution to the existing body of knowledge.

Finally, this research study points out that amongst the project factors, contractors, consultants and project management tools/techniques factors are highly significant in determining project performance of the construction companies in Iraq. Similarly, with regards to the organizational factors, organization culture and learning organization factors are found to be significant. The above results do not concur in totality with previous research results. In some of the past research results, leadership is found as significant and in some other research, innovation is found as an important factor. The reasons for the contradicting results of this research study may be examined in future research to find out why and how these factors differ in this study in comparison to the other studies.

\section{CONCLUSION}

In conclusion, this research study achieved its research objectives by examining and investigating the various project and organizational factors which significantly impact project performance of the overall construction industry and for the major construction sectors, i.e., civil, building and infrastructure, marine, oil and gas and multidiscipline construction sectors. The findings of this study provide a comprehensive understanding on the various project and organizational factors, which are essential for achieving the desired project performance in different construction sectors of Iraq. The findings of this study emphasize the need to focus on organizational related factors, such as organizational culture, learning organization, leadership and innovation along with the project factors such as contractors, consultants and material for successful project performance. This is due to the industry observation that, the old paradigms on project management are changing rapidly due to technological developments happening in the industry.

\section{REFERENCES}

[1]. Alnaas, K. A. A., Khalil, A. H. H., \& Nassar, G. E. (2014). Guideline for preparing comprehensive extension of time (EOT) claim. HBRC Journal, 10(3), pp. 308- 316.

[2]. Alnuaimi, A.S. et al., 2010. Causes, effects, benefits, and remedies of change orders on public construction projects in Oman.

[3]. Long, H., \& Lien, Y. (2018). ScienceDirect Goal orientations, leader-leader exchange, trust, and the outcomes of project performance. International Journal of Project Management, 36(5), 716-729. https://doi.org/10.1016/j.ijproman.2018.03.009.

[4]. Kissi, E, Agyekum, K, Baiden, B.K, Tannor, R.A, Asamoah, G.E, Andam, E.T, Baiden, B.K.(2019). Impact of proj monitor \& evaluate practice on construction projt success criteria in Ghana. Built Environment Project \& Asset Mngnt. https://doi.org/10.1108/BEPAM-11-2018-0135.

[5]. Egwunatum, S. I. (2018). MOJ Civil Engineering A Review of Construction Project Performance Estimators. MOJ Civil Eng 2017, 3(4) (September 2017), 14-17. https://doi.org/10.15406/mojce.2017.03.00075

[6]. Rooij, M.M.G.De, Janowicz-panjaitan, M, \& Mannak, R.S. (2019). ScienceDirect A configurational exp for performance management systems' design in project-based organizations. International Jour of Project Mangnt, 37(5), 616-630. https://doi.org/10.1016/j.ijproman.2019.03.002.

[7]. Construction industry transformation program (2015), Construction Industry Development Board, Malaysia. retrieved on-line on November, 2015. http://www.cidb.gov.my/cidbv5/index.php/warga-cidb

[8]. Larsson, J. (2018). The importance of hard project management and team motivation for construction project performance. International Journal of Managing Projects in Business, 11(2), 275-288. https://doi.org/10.1108/IJMPB-04-2017-0035.

[9]. De Vaus, D., \& de Vaus, D. (2013). Surveys in social research: Routledge.

[10]. De Vries, N. J., \& Carlson, J. (2014). Examining the drivers and brand performance implications of customer engagement with brands in the social media environment. Journal of Brand Management, 21(6), 495-515.

[11]. Abdullah A. Khawam, Nancy S. Bostain, (2019). Project manager's role in safety performance of Saudi construction. International Journal of Managing Projects in Business. https://doi.org/10.1108/IJMPB-04-2018-0087

[12]. Moschouli, E., Murwantara, R., \& Vanelslander, T. (2019). Research in Transportation Economics Cost performance of transport infrastructure projects before and after the global financial crisis ( GFC ): Are differences observed in the conditions of project performance? Research in Transportation Economics, (February), 1-15. https://doi.org/10.1016/j.retrec.2019.02.004. 


\title{
International Advanced Research Journal in Science, Engineering and Technology
}

\author{
Vol. 6, Issue 6, June 2019
}

[13]. Hussein, B.A, Ahmad, S.B, \& Zidane, Y.J. (2015). Problem associated with defining project success. Procedia Computer Science, 64, 940-947.

[14]. Sirisomboonsuk, P., Ching, V., Qing, R., \& Burns, J. R. (2018). ScienceDirect Relationships between project governance and information technology governance and their impact on project performance. International Journal of Project Management, 36(2), 287-300. https://doi.org/10.1016/j.ijproman.2017.10.003.

[15]. Alaloul, W. S., Liew, M. S., Amila, N., \& Abdullah, W. (2016). Identification of coordination factors affecting building projects performance. Alexandria Engineering Journal, 55(3), 2689-2698. https://doi.org/10.1016/j.aej.2016.06.010.

[16]. Jabatan Laut Malaysia. (2015). List of Malaysian containers, oil tankers and fishing ports. retrieved on-line on November, 2015. www.marine.gov.my. www.mot.gov.my.

[17]. Malaysia household debt to GDP. (2013). retrieved on-line on November, 2015. https://www.google.com/search?q=bank+negara+malaysia+ household+debt.

[18]. Malaysia oil and gas report. (2016), retrieved on-line on November, 2015. https://community.ump.edu.my/ecommstaff/sites/default/library/ subfolders/1278 0/1/BMI_Malaysia_Oil_26_Gas_Report_Q12016.pdf.

[19]. Marzook, M.M, \& El-Rasas, T.I. (2014). Analyzing delay causes in Egyptian construction projects. Journal of Advanced Research, 5(1), 49-55.

[20]. Olugbenga Jide Olaniran, (2015). (2015). The effects of cost-based contractor selection on construction project performance. Journal of Financial Management of Property and Construction, 20(3), 235-251. https://doi.org/10.1108/JFMPC-06-2014-0008.

[21]. Gefen, D., and Straub, D. (2005). A practical guide to factorial validity using PLS-graph: Tutorial and annotated example. Communications of the Association for Information Systems, 16(25), 91-109.

[22]. Sami Kärnä, Juha-Matti Junnonen, (2016). (2016). Benchmarking construction industry , company and project performance by participants ' evaluation. Benchmarking: An International Journal, 23(7), 2092-2108. https://doi.org/10.1108/BIJ-05-2015-0050.

[23]. Van Berkel, F.J., Ferguson, J.E., \& Groenewegen, P. (2016). Speedy delivery versus long term objectives: How time pressure affects coordination between temporary projects and permanent organizations. Journal of Long-Range Planning.

[24]. Van Offenbeek, M.A., \& Vos, J.F. (2016). An integrative framework for managing project issues across stakeholder groups. International Journal of Project Management, 34(1), 44-57.

[25]. Demirkesen, S., \& Ozorhon, B. (2017). ScienceDirect Impact of integration management on construction project management performance. International Journal of Project Management, 35(8), 1639-1654. https://doi.org/10.1016/j.ijproman.2017.09.008.

[26]. Olugbenga Jide Olaniran, (2015). (2015). The effects of cost-based contractor selection on construction project performance. Journal of Financial Management of Property and Construction, 20(3), 235-251. https://doi.org/10.1108/JFMPC-06-2014-0008.

[27]. Zidane, Y. J., Hussein, B. A., \& Ørn, J. (2016). Categorization of organizational factors and their impact on project performance. Procedia Social and Behavioral Sciences, 226(1877), 162-169. https://doi.org/10.1016/j.sbspro.2016.06.175.

[28]. Kobarg, S., Stumpf-wollersheim, J., \& Welpe, I. M. (2019). More is not always better : E ff ects of collaboration breadth and depth on radical and incremental innovation performance at the project level. Research Policy, 48(1), 1-10. https://doi.org/10.1016/j.respol.2018.07.014.

[29]. Agung, M., Yudha, I. N., \& Rusdi, H. A. (2015). An analysis of bidding strategy, project performance and company performance relationship in construction. Procedia Engineering, 125, 95-102. https://doi.org/10.1016/j.proeng.2015.11.015.

[30]. Al-sibaie, E. Z., \& Alashwal, A. M. (2014). Determining the relationship between conflict factors and performance of international construction projects. Engineering, Construction and Architectural Management, 21(4), 369-382. https://doi.org/10.1108/ECAM-03-2014-0034.

[31]. Blomquist, T., Dehghanpour, A., \& Thomas, J. (2016). ScienceDirect Project management self-ef fi cacy as a predictor of project performance : Constructing and validating a domain-speci fi c scale. JPMA, 34(8), 1417-1432. https://doi.org/10.1016/j.ijproman.2016.07.010.

[32]. Cannon, J., Sousa, P., Katara, I., Beveridge, D., Holt, T. Van, Veiga, P., \& Spear, B. (2018). Fishery improvement projects : Performance over the past decade. Marine Policy, 97(June), 179-187. https://doi.org/10.1016/j.marpol.2018.06.007

[33]. Dubem Isaac Ikediashi, Amaka Chinweude Ogwueleka, (2016). Assessing the use of ICT systems and their impact on construction project performance in the Nigerian construction industry. Journal of Engineering, Design and Technology, 14(2), 252-276. https://doi.org/10.1108 /JEDT-08-2014-0047.

[34]. Fan, W. (2013). Improving performance of construction projects A project manager's s emotional. Engineering, Construction and Architectural Management, 20(2), 195-207. https://doi.org/10.1108/09699981311303044.

[35]. Lei, Z., Tang, W., Duf, C., Zhang, L., Kin, F., \& Hui, P. (2017). ScienceDirect The impact of technical standards on international project performance: Chinese contractors ' experience. International Journal of Project Management 35 (2017) 1597-1607 Www.Elsevier.Com/Locate /Jjproman, 35, 1597-1607. https://doi.org/10.1016/j.ijproman.2017.09.002.

[36]. Lianying Zhang, Xiaoyan Huo, (2015). (2015). The impact of interpersonal conflict on construction project performance A moderated mediation study from China. International Journal of Conflict Management, 26(4), 479-498. https://doi.org/10.1108/IJCMA-09-2014-0072.

[37]. Mikael Frödell, Per-Erik Josephson, Göran Lindahl, (2008) "Swedish. (2008). Swedish construction clients ' views on project success and measuring performance. Journal of Engineering, Design and Technology. https://doi.org/10.1108/17260530810863316.

[38]. Mohamed Mahdy Marzouk, Emad Fayez Gaid, (2018). Assessing Egyptian construction projects performance using principal component analysis. International Journal of Productivity and Performance Management, 67(9), 1727-1744. https://doi.org/10.1108/IJPPM-06-2017-0134. 